\section{PENGEMBANGAN SEKOLAH INKLUSI DENGAN PEMANFAATAN MEDIA VISUAL SCRATCH DAN ALAT PERAGA MANIPULATIF}

Ukhti Raudhatul Jannah"*, Fauzan Prasetyo Eka Putra ${ }^{2}$, Ainur Rofia Hafsi $^{3}$, Hasan Basri ${ }^{1}$

\section{1)Pendidikan}

Universitas Madura

2)Teknik Informatika, Universitas Madura

3)Pendidikan Bahasa Indonesia, Universitas Madura

\begin{tabular}{lll}
\multicolumn{2}{l}{ Article history } & \\
Received & 13-10-2020 \\
Revised & $:$ & $09-02-2021$ \\
Accepted & $:$ & $18-03-2021$
\end{tabular}

\section{*Corresponding author}

Ukhti Raudhatul Jannah

Email: ukhti_math@unira.ac.id

\begin{abstract}
Abstrak
Tujuan kegiatan pengabdian ini adalah mengembangkan Sekolah Inklusi dengan pemanfaatan media visual scratch dan alat peraga manipulatif dalam pemahaman konsep perkalian bilangan bulat di SDN Lawangan Daya 2 Pamekasan. Sekolah Dasar Negeri (SDN) Lawangan Daya 2 Pamekasan merupakan salah satu sekolah inklusi di kabupaten Pamekasan dengan 3 siswa ABK (berkesulitan belajar, lamban belajar, dan tunagrahita ringan) pada kelas 3. Akan tetapi yang ikut kegiatan ini 2 siswa ABK (berkesulitan belajar, lamban belajar) sesuai ijin orang tua karena asa pandemic covid 19. Media visual scratch adalah media pembelajaran visual untuk penanaman konsep perkalian dengan animasi yang dibuat dengan bahasa pemrograman. Alat manipulatif dari benda konkret yang bisa dipegang, di raba, dan di manipulasi oleh siswa sebagai media pembelajaran untuk penanaman konsep matematisnya. Metode pelaksanaan yang digunakan pada kegiatan ini adalah (1) persiapan (Introduction, Edukasi), (2) Pelaksanaan (Pembelajaran, Workshop), (3) Evaluasi (Pemahaman, Pengenalan). Berdasarkan hasil dari kegiatan ini adalah adanya peningkatan pemahaman konsep perkalian bilangan pada siswa ABK dan kegiatan workshop pada guru-guru berjalan dengan baik, yang dibuktikan guru antusias dalam mempraktekkan bahan manipulatif dan mampu membuat program scratch. Kegiatan ini dapat dijadikan bahan acuan pembelajaran pada materi lainnya khususnya perkalian bilangan bulat pada sekolah lainnya.
\end{abstract}

Kata Kunci: Media Manipulatif; Media Visul Scratch; Sekolah Inklusi

\section{Abstract}

This service activity aims to develop an inclusive school by utilizing visual scratch media and manipulative props in understanding the concept of multiplication of integers at SDN Lawangan Daya 2 Pamekasan. Lawangan Daya 2 Pamekasan Public Elementary School (SDN) is one of the inclusion schools in the Pamekasan district with three special needs students (learning difficulties, slow learning, and mild mental retardation) in grade 3. However, two students with special needs (learning difficulties, slow to learn) according to parental consent due to the Covid 19 pandemic. Visual scratch media is a visual learning medium for planting the concept of multiplication with animation created in a programming language. Manipulative tools from concrete objects that students can hold touch, and manipulate as a learning medium for planting mathematical concepts. The implementation method used in this activity is (1) preparation (Introduction, Education), (2) Implementation (Learning, Workshop), (3) Evaluation (Understanding, Introduction). Based on this activity's results, there was an increase in the understanding of the multiplication concept of numbers for ABK students. The workshop activities for teachers were going well, which was proven by the teacher being enthusiastic in practicing manipulative materials and making scratch programs. This activity can be used as a reference for learning in other materials, especially the multiplication of integers in other schools.

Keywords: Manipulative Media; Visual Scratch Media; Inclusive Schools 


\section{PENDAHULUAN}

Pendidikan khusus merupakan pendidikan bagi peserta didik yang memiliki tingkat kesulitan dalam mengikuti proses pembelajaran karena kelainan fisik, emosional, mental, sosial, dan/atau memiliki potensi kecerdasan dan bakat istimewa (Undang-undang Republik Indonesia nomor 20 tahun 2003). Pendidikan khusus menjadi perhatian bagi pemerintah dalam pemerataan pendidikan bagi Anak Berkebutuhan Khusus ( $A B K$ ) dan siswa normal. Untuk pemerataan pendidikan ini, selain adanya pendidikan khusus bagi $A B K$, maka pemerintah mencanangkan pendidikan inklusi.

Pendidikan inklusi merupakan penggabungan penyelenggaraan pendidikan luar biasa dengan pendidikan reguler dalam satu sistem pendidikan yang dipersatukan (Peraturan Menteri Pendidikan Nasional Nomor 70 Tahun 2009). Pendidikan inklusi adalah penyelenggaraan pendidikan yang menyatukan anak-anak berkebutuhan khusus dengan anak-anak normal pada umumnya untuk belajar (Smith, 2006). Pendidikan inklusi merupakan sistem penyelenggaraan pendidikan dan pembelajaran yang memuat siswa berkebutuhan khusus dan siswa normal yang bertujuan adanya pemerataan pendidikan. Bentuk kelainan yang dilayani melalui pendidikan inklusi menurut Peraturan Menteri Pendidikan Nasional Nomor 70 Tahun 2009 dapat berupa: tunanetra, tunarungu, tunawicara, tunalaras, tunadaksa, tunagrahita, berkesulitan belajar, lamban belajar, autis, memiliki gangguan motorik, menjadi korban penyalahgunaan narkoba, obat terlarang, dan zat adiktif lainnya, memiliki kelainan lainnya, dan tunaganda.

Di Kabupaten Pamekasan, terdapat 78 SDN inklusi, akan tetapi sekolah ini belum benar- benar menerapkan pembelajaran kelas inklusi. Sekolahsekolah tersebut dinamakan sekolah inklusi karena terdapat siswa-siswa yang berkebutuhan khusus. Salah satunya SDN Lawangan Daya 2 Pamekasan. Di SDN Lawangan Daya 2, kelas inklusi terdapat pada kelas III yang terdiri dari tiga orang siswa yang mengalami kelainan dalam berkesulitan belajar (1 siswa), siswa lamban belajar (1 siswa), dan siswa tunagrahita ringan (1 siswa). Ketiga siswa ini prestasinya rendah dan kesulitan dalam memahami konsep perkalian bilangan bulat yang sudah dipelajari sejak kelas 2.

Di sekolah inklusi ini, kurikulum dan pembelajaran yang diterapkan di sekolah masih disamakan dengan kelas reguler. Perlakuan pada siswa yang berkebutuhan khusus adalah sama karena kondisi kelas tidak dibuat peer tutoring (tutor sebaya). Anak yang berkebutuhan khusus cenderung ditinggalkan oleh guru jika tidak paham terhadap materi pelajaran, dan alat pembelajarannya tidak digunakan dengan baik pada siswa, terutama media pembelajaran dan alat peraga untuk penanaman konsep perkalian bilangan bulat bagi siswa berkebutuhan khusus dan siswa reguler. Kejenuhan siswa belajar juga muncul ketika media pembelajaran matematika dan proses pembelajaran yang digunakan guru tidak terkait dengan permasalahan kehidupan sehari-hari siswa (Jannah et al., 2018).

Berdasarkan berbagai permasalahan yang dihadapi mitra yaitu SDN Lawangan Daya 2, Tim PKM akan membuat media pembelajaran dengan program visual scratch dengan animasi pembelajaran dan alat peraga manipulatif pada siswa di kelas inklusi terutama bagi siswa berkebutuhan khusus agar mampu memahami dan melakukan operasi perkalian pada bilangan bulat. Selama ini siswa ABK belajar perkalian bilangan secara abstrak sehingga konsep perkalian tersebut belum dipahami dengan baik. Melalui alat peraga manipulative, siswa $A B K$ diharapkan bisa belajar melalui manipulasi benda konkret untuk menemukan konsep perkalian bilangan. Program ini juga dapat meningkatkan mutu pendidikan di Indonesia khususnya di Pamekasan sehingga terjadi pemerataan pemerolehan pendidikan bagi Anak Berkebutuhan Khusus (ABK) dan anak normal.

Scratch merupakan pemrograman visual untuk pembelajaran bagi siswa, guru, dan orang tua tanpa harus menuliskan salah benar penulisan sintaksis (Pratiwi et al., 2017) dengan menggunakan sebuah bahasa pemrograman (Resnick et al., 2009). Scratch ini yang akan tim PKM gunakan di sekolah inklusi untuk mengatasi permasalahan di kelas inklusi dalam pemahaman konsep perkalian bilangan, konsentrasi belajar siswa, meningkatkan kemampuan visual, membaca, dan berhitung bagi siswa terutama siswa berkebutuhan khusus di kelas inklusi.

Alat peraga yang akan digunakan berupa alat peraga yang sesuai dengan animasi di dalam media visual scratch. Penggunaan alat peraga ini bertujuan untuk memudahkan siswa memahami konsep melalui praktek langsung, memfokuskan konsentrasi belajar siswa, melatih visual siswa dan kelancaran membacanya. Alat peraga dan media visual scratch ini juga menarik bagi siswa terutama bagi siswa $A B K$, karena selain belajar, siswa juga akan bermain. Siswa ABK pada kegiatan ini lamban belajar dan tunagrahita ringan sehingga media visual scratch dan alat peraga manipulatif melatih konsentrasi belajar siswa dan menarik minat belajar siswa yang lamban belajar karena memanipulasi langsung benda nyata, serta belajar dengan permainan. Hal ini sesuai pendapat Jannah (2013) bahwa jika konsep matematika diajarkan dengan permainan, maka siswa akan lebih tertarik untuk 
belajar. Tujuan dari program pengabdian ini adalah mengembangkan Sekolah Inklusi dengan pemanfaatan media visual scratch dan alat peraga manipulatif dalam pemahaman konsep perkalian bilangan bulat.

\section{METODE PELAKSANAAN}

Kegiatan ini dilakukan di SDN Lawangan Daya 2 Pamekasan pada kelas III. Di kelas III ini terdapat 3 siswa ABK yaitu siswa berkesulitan belajar, siswa lamban belajar, dan siswa tunagrahita ringan. Pada saat kegiatan, hanya 2 siswa ABK yang diijinkan karena terkait masa pandemic covid 19 yaitu siswa lamban belajar dan siswa tunagrahita ringan. Metode pelaksanaan yang akan dilakukan untuk mengembangkan Sekolah Inklusi dengan pemanfaatan media visual scratch dan alat peraga manipulatif dalam pemahaman konsep perkalian bilangan bulat.

Tahap perencanaan berupa introduction dan edukasi. Observasi pada sekolah inklusi di kelas III SDN Lawangan Daya 2 Pamekasan dan terdapat 3 anak berkebutuhan khusus (berkesulitan belajar, lamban belajar, dan tunagrahita ringan). Wawancara dilakukan pada Kabag pembelajaran SD di dinas pendidikan dan guru kelas III sebagai pengajar di kelas inklusi. Kegiatan edukasi berupa pembuatan media visual animasi scratch dan alat peraga manipulatif untuk pemahaman konsep perkalian bilangan, kemampuan visual, dan kemampuan membaca.

Tahap pelaksanaan terdiri dari praktek pembelajaran dan workshop. Praktek penggunaan media visual scratch dan praktek alat peraga manipulatif sesuai pembelajaran menggunakan scratch dan alat peraga manipulatif. Praktek pembelajaran ini dilakukan dengan pembelajaran langsung ke masing-masing individu di rumah masing-masing siswa ABK. Praktek pembelajaran ini divideokan dan di upload ke youtube. Workshop sekolah inklusi dan pembelajarannya, dan workshop penggunaan media visual scratch dan alat peraga manipulatif bagi guru-guru SD inklusi. Workshop dilakukan secara daring melalui zoom dengan guruguru SDN Lawangan Daya 2.

Tahap evaluasi berupa tahap pemahaman dan pengenalan. Proses pembelajaran dengan penggunaan media visual scratch dan alat peraga manipulatif akan meningkatkan pemahaman konsep perkalian bilangan bulat, visual, konsentrasi belajar, dan kemampuan membaca. Peningkatan pemahaman perkalian bilangan bulat ditunjukkan dengan kemampuan siswa ABK memecahkan masalah yang berkaitan dengan perkalian bilangan bulat. Setelah workshop dilakukan secara daring, guru-guru diharapkan mengenal dan menerapkan pembelajaran dengan media manipulatif, selain itu guru-guru juga akan mampu mengaplikasikan media visual scratch dengan baik dan menarik bagi siswa.

\section{PEMBAHASAN \\ Perencanaan}

Ada beberapa Sekolah inklusi di Kabupaten Pamekasan saat ini. Untuk memperoleh data yang akurat, maka dilakukan wawancara pada Kabag Pendidikan Sekolah Dasar di dinas pendidikan Pamekasan. Informasi yang diperoleh dari hasil wawancara tersebut adalah terdapat 78 SDN inklusi di Kabupaten Pamekasan (Gambar 1), akan tetapi sekolah ini belum benar- benar menerapkan pembelajaran kelas inklusi. Menurut Hermanto (2010), pentingnya manajemen sekolah inklusif untuk menjamin pelayanan pendidikan anak berkebutuhan khusus. Anak berkebutuhan khusus yang bersekolah di sekolah regular memiliki kompetensi sosial yang lebih baik (Loiacono \& Valenti, 2010).
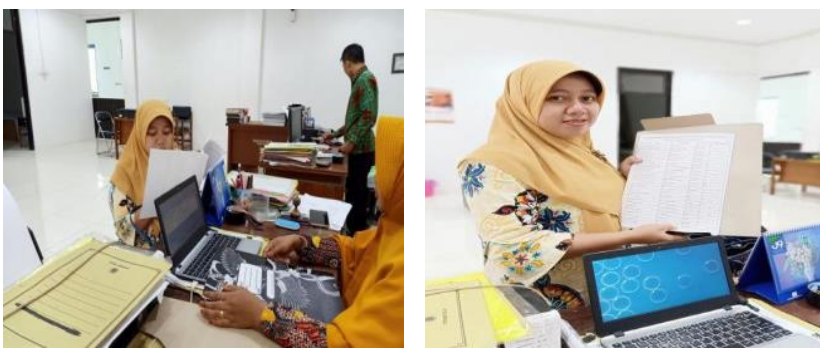

Gambar 1. Perolehan informasi sekolah inklusi di Dinas Pendidikan Kabupaten Pamekasan

Berdasarkan hasil wawancara dengan bagian pendidikan di dinas pendidikan dan observasi ke sekolah-sekolah, Tim memilih Lada 2 sebagai sekolah yang akan dikenalkan dengan pembelajaran media manipulatif dan media visual scratch. Setelah itu, dilakukan wawancara dengan guru kelas dan siswa ABK yang ada di kelas 3 (Gambar 2).

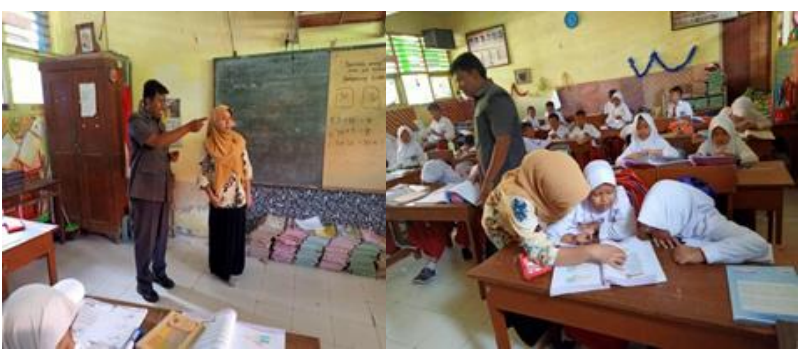

Gambar 2. Observasi dan wawancara dengan guru pengajar kelas inklusi

Di SDN Lawangan Daya 2, kelas inklusi terdapat pada kelas III yang terdiri dari tiga orang siswa yang mengalami kelainan dalam berkesulitan belajar (1 siswa), siswa lamban belajar (1 siswa), dan 
siswa tunagrahita ringan ( 1 siswa). Ketiga siswa ini kesulitan dalam memahami materi matematika terutama dalam mengoperasikan perkalian bilangan yang sudah dipelajari sejak kelas 2 dan menjadi modal dasar pemahaman materi matematika. Selain itu, ketiga siswa ini memiliki prestasi yang sangat rendah dibandingkan dengan temanteman sekelasnya akibat kesulitan belajarnya dan lamban dalam memahami materi matematika. Untuk siswa tunagrahita ringan, siswa ini juga kesulitan membaca dan berhitung. Keadaan di SDN Lawangan daya 2 ini sesuai dengan pernyataan Tarmansyah (2007) mengemukakan bahwa pendidikan inklusi adalah penempatan anak berkelainan tingkat ringan, sedang dan berat secara penuh di kelas reguler.

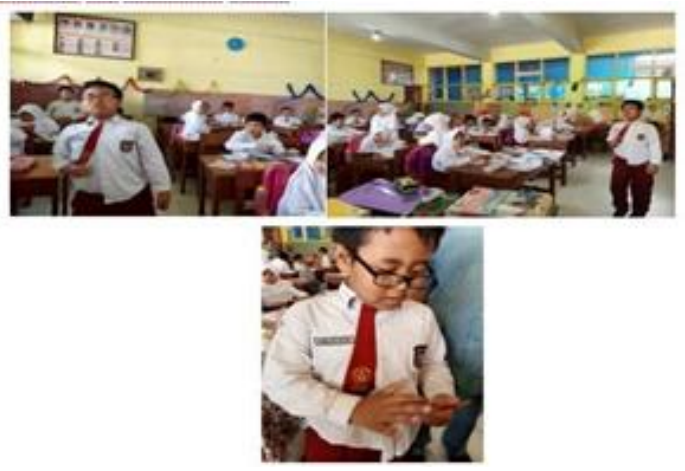

Gambar 3. Siswa 1 berkesulitan belajar

Siswa 1 tidak mampu berkonsentrasi ketika proses pembelajaran, tidak melakukan dan tidak memahami apa yang diperintah guru dengan menggambar robot tanpa mengerjakan tugasnya (Gambar 3). Selain itu, ketika ditanya tentang perkalian bilangan, siswa 1 menghitung menggunakan bantuan jari untuk menentukan hasil perkalian dan tidak mampu menjawab dengan benar. Siswa ini dikategorikan siswa berkesulitan belajar karena tidak mampu berkonsentrasi, dan pemahaman konsep yang tidak tepat mengakibatkan kemampuan dan prestasinya rendah.
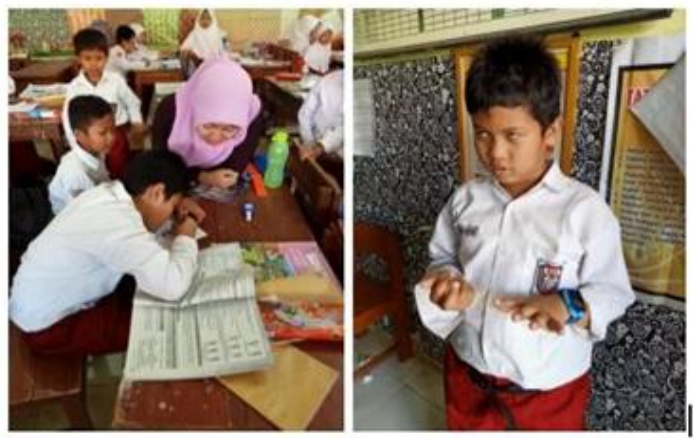

Gambar 4. Siswa 2 lamban belajar

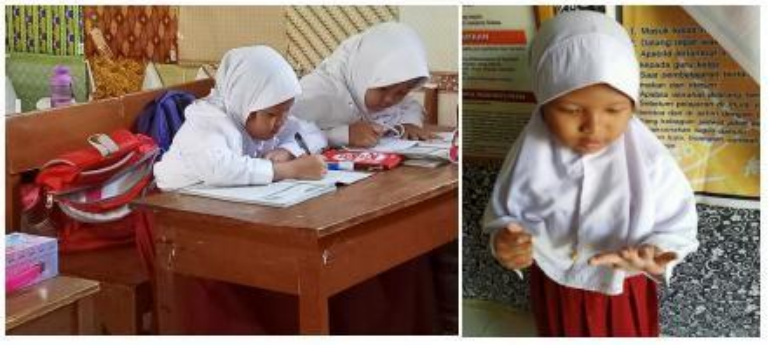

Gambar 5. Siswa 3 tunagrahita ringan

Siswa 2 hyper aktif tanpa mempedulikan lingkungan, tidak mengerjakan tugas, tidak memperhatikan penjelasan dan perintah guru, tidak berkonsentrasi dalam belajar, dan tidak mampu mengoperasikan perkalian bilangan dengan benar (Gambar 4). Siswa 3 adalah siswa yang mengalami tunagrahita ringan, pendiam, mengerjakan tugas tetapi jawabannya salah, kemampuannya sangat rendah, kemampuan membaca dan menghitungnya rendah, dan tidak mampu mengoperasikan perkalian bilangan dengan benar (Gambar 5). Siswa 2 dan siswa 3 dikategorikan siswa yang lamban dalam belajar dan berkemampuan sangat rendah. Anak tunagrahita kecerdasannya jauh dibawah rata-rata, ditandai keterbatasan intelegensi, dan ketidakcakapan dalam interaksi sosialnya sehingga kesulitan mengikuti pembelajaran di sekolah umum (Jannah et al., 2019).
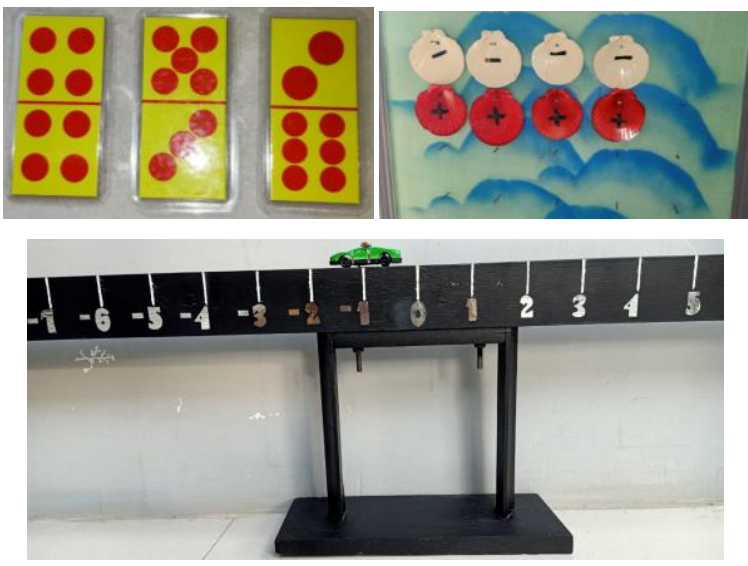

Gambar 6. Media manipulatif perkalian bilangan bulat

Untuk membantu belajar siswa khususnya siswa ABK di kelas Inklusi dalam memahami konsep perkalian bilangan bulat, Tim PKM membuat alat peraga manipulatif (Gambar 6) dan media visual scratch (Gambar 7). Pembelajaran di Sekolah Dasar lebih menekankan pada media manipulatif dari benda konkret yang bisa di pegang, di raba, dan dimanipulasi oleh siswa sebagai media pembelajaran untuk penanaman konsep matematisnya. 
Pembelajaran ini sesuai dengan teori belajar Bruner dimana seseorang dapat menyusun hipotesis untuk memasukkan pengetahuan baru ke dalam struktur yang telah dimilikinya atau mengembangkan struktur baru (Aisyah et al., 2007). Media manipulatif yang digunakan dalam pembelajaran ini adalah kartu domino, kulit kerang, dan garis bilangan.

Media visual scratch merupakan media pembelajaran visual untuk penanaman konsep perkalian dengan animasi yang dibuat dengan bahasa pemrograman. Hal ini sesuai dengan pernyataan Resnick (2009) bahwa scratch merupakan sebuah bahasa pemrograman yang digunakan untuk pembuatan media pembelajaran. Alat peraga dan media visual scratch ini juga menarik bagi siswa, karena selain belajar, siswa juga akan bermain. Hal ini sesuai pendapat Jannah (2013) bahwa jika konsep matematika diajarkan dengan permainan, maka siswa akan lebih tertarik untuk belajar.
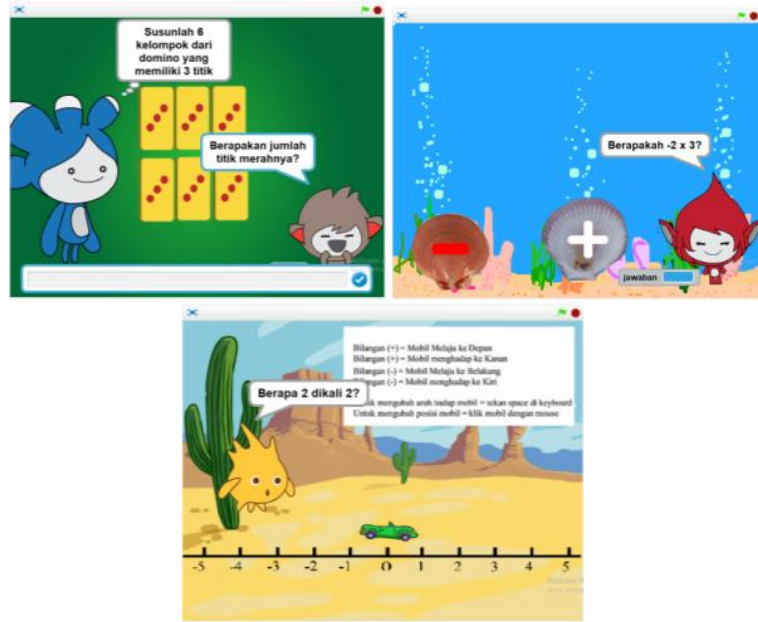

Gambar 7. Media visual scratch perkalian bilangan bulat

\section{Pelaksanaan}

Pelaksanaan pembelajaran dilakukan 01 - 06 Juli 2020. Pembelajaran dilakukan di rumah masingmasing siswa $A B K$ ( $A B K 1$ dan $A B K 2)$ oleh Tim PKM karena pada saat itu terjadi pandemi Covid 19, sedangkan 1 siswa ABK tidak diijinkan oleh orang tuanya. Penerapan media manipulatif dilakukan pada siswa $A B K 1$ dan $A B K 2$. Berdasarkan wawancara dengan orang tua siswa, $A B K 1$ memiliki kelemahan dalam memahami materi sehingga berdampak pada prestasinya rendah di sekolah. Pada saat pembelajaran, siswa ABK 1 (Gambar 8) dan siswa ABK2 (Gambar 9) lebih konsentrasi dan aktif belajar menggunakan media manipulatif dan media scratch. Siswa ABK1 dan ABK2 berhadapan langsung dengan media konkretnya untuk memanipulasi kartu domino, kulit kerang, dan garis bilangan dalam memahami dan menemukan konsep perkalian bilangan bulat. Pembelajaran ini telah dirancang agar siswa ABK tertarik dan fokus dalam belajar, serta memahami konsep perkalian bilangan bulat dengan baik. Pembelajaran matematika merupakan proses pengalaman belajar kepada siswa melalui serangkaian kegiatan yang terencana sehingga siswa memperoleh kompetensi yang baik tentang materi matematika yang dipelajari (Muhsetyo et al., 2014).

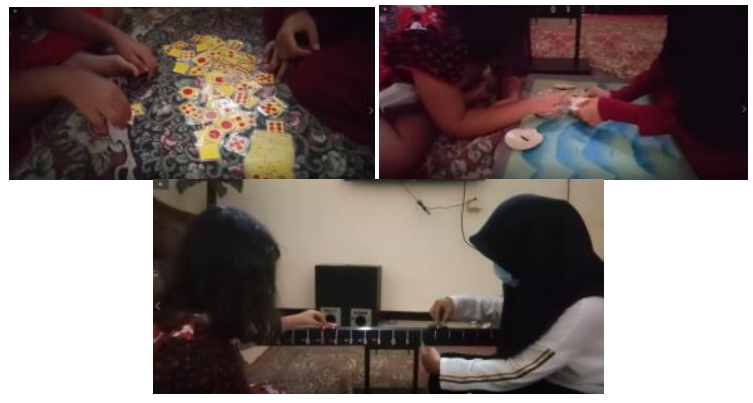

Gambar 8. Pembelajaran pada siswa ABK1

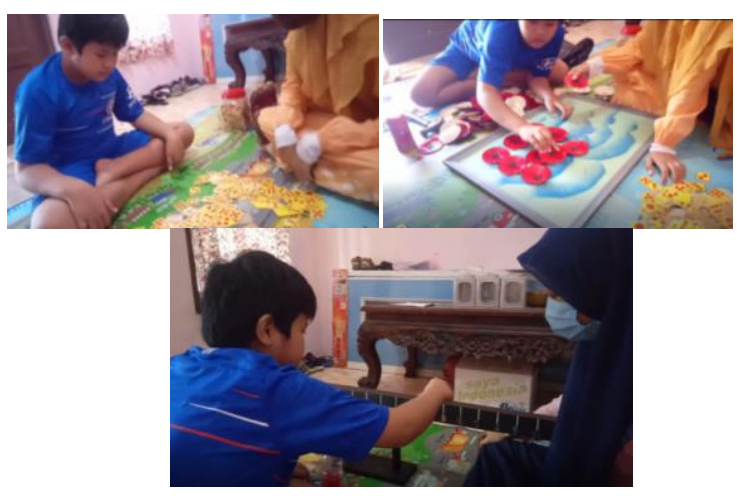

Gambar 9. Pembelajaran pada siswa ABK2

Setelah melakukan pembelajaran perkalian bulat dengan media manipulatif benda konkret, dilanjutkan pembelajaran menggunakan media semi konkret menggunakan media visual scratch berupa game online. Siswa ABK1 dan ABK2 (Gambar 10) semakin tertarik dengan pembelajaran dan materinya karena gambarnya menarik dan mereka dapat belajar sambil bermain. Scratch dapat digunakan untuk membuat aplikasi, animasi, games, dan merupakan salah satu media pembelajaran berkonsep edutainment bagi para pengajar (Iskandar \& Raditya, 2017).

Meskipun kegiatan ini terdapat beberapa kendala, yaitu pembelajaran dilaksanakan secara individu di rumah masing-masing siswa $A B K$ dan workshop dilakukan secara online melalui zoom karena pandemi covid 19, dan program scratch memakai laptop karena tidak support menggunakan Tablet, tetapi pembelajaran dapat berlangsung dengan baik dan sesuai dengan tujuan kegiatan yang ingin dicapai. 


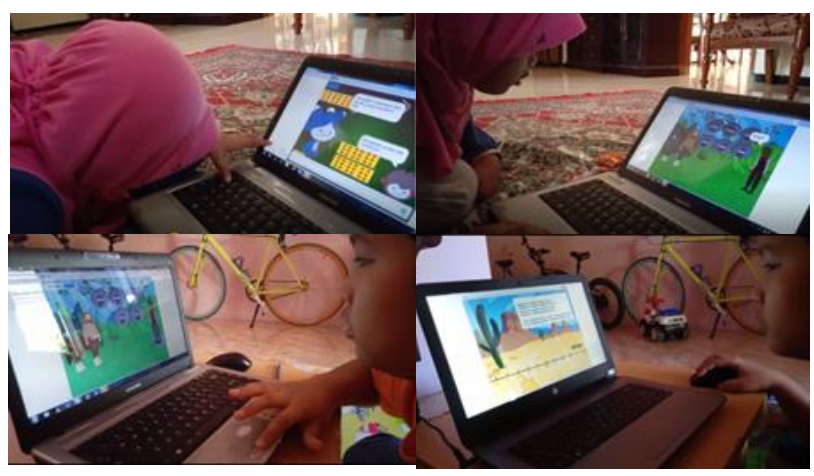

Gambar 10. Pembelajaran media scratch pada $A B K 1$ dan $A B K 2$

\section{Evaluasi \\ Pemahaman}

Sebelum melakukan kegiatan pengembangan pembelajaran menggunakan media manipulatif dan media scratch, 2 siswa ABK diberikan tes awal untuk mengetahui pemahaman siswa tentang konsep perkalian bilangan bulat. Berdasarkan hasil tes dari 5 soal menunjukkan bahwa siswa ABK 1 benar 1 soal, sedangkan siswa ABK 2 benar 2 soal. siswa ABK masih kesulitan memahami dan memecahkan masalah yang berkaitan dengan konsep perkalian bilangan bulat (Gambar 11).

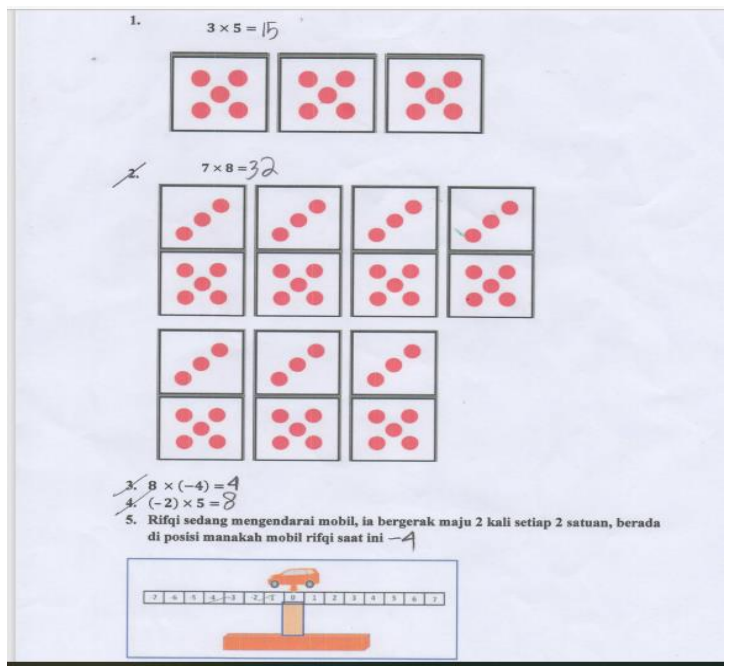

Gambar 11. Hasil pre-tes siswa ABK

Setelah dilakukan kegiatan pembelajaran perkalian bilangan bulat dengan media visual scratch dan media manipulative menunjukkan antusiasme siswa ABK belajar dalam memanipulasi alat peraga manipulatif dan belajar dengan bermain melalui media visual scratch. Hal ini ditunjukkan juga dari hasil post tes siswa ABK yang menunjukkan mampu memecahkan masalah yang berkaitan dengan perkalian bulat sehingga pemahaman konsep perkalian bilangan siswa $A B K$ sangat baik (Gambar 12). Secara keseluruhan menunjukkan peningkatan yang memuaskan. Dari hasil post test yang diberikan setelah kegiatan menunjukkan siswa $A B K 1$ dan siswa $A B K 2$ mampu memecahkan semua masalah dengan benar (Gambar 13). Keberhasilan pembelajaran ditunjukkan oleh dikuasainya materi pembelajaran oleh siswa. Salah satu faktor keberhasilan dalam pembelajaran adalah kemampuan guru dalam merencanakan dan melaksanakan pembelajaran (Amir, 2014).

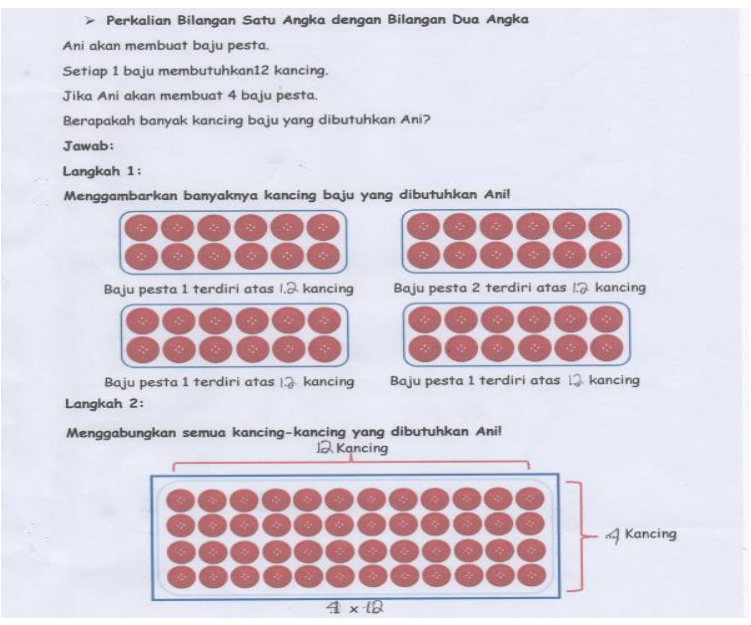

Gambar 12. hasil post-tes siswa ABK

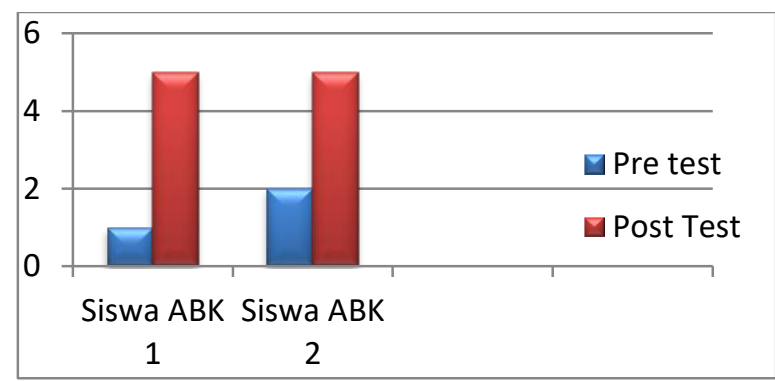

Gambar 13. Hasil pre tes dan post tes siswa ABK

\section{Workshop}

Workshop dilakukan pada guru-guru SDN Lawangan Daya 2 Pamekasan sejumlah 22 guru yang terdiri dari guru kelas 1 sampai kelas 6 yaitu 19 guru kelas dan guru mata pelajaran matematika, 3 guru perwakilan dari kepala sekolah, wakil kepala sekolah, dan waka kurikulum.

Sebelum pelatihan dan workshop dilakukan peserta diminta untuk mengisi Google Form, untuk mengetahui bagaimana pemahaman guru terhadap media scratch dan media manipulatif. Berikut ini data yang diperoleh berdasarkan isian Google Form dari peserta pelatihan dan workshop 
dengan responden 19 guru kelas dan guru mata pelajaran matematika (Gambar 14).

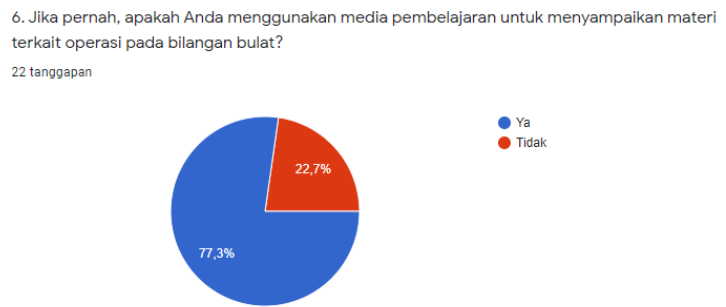

8. Apakah Anda pernah menggunakan media scratch?

22 tanggapan

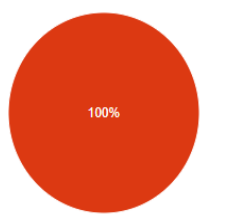

- Ya

Gambar 14. Hasil pre test mengenai media pembelajaran dalam proses pembelajaran

Berdasarkan Gambar 14 terlihat bahwa mayoritas para peserta workshop tidak pernah menggunakan media pembelajaran dalam proses pembelajaran. Selain itu diperoleh informasi bahwa semua peserta belum pernah menggunakan media scratch. Dienes mengemukakan bahwa tiap-tiap konsep atau prinsip dalam matematika yang disajikan dalam bentuk yang konkret akan dapat dipahami dengan baik (Jannah, 2013). Hal ini menunjukkan bahwa scratch akan menjadi hal baru bagi peserta pelatihan dan workshop media pembelajaran ini.

Setelah peserta pelatihan dan workshop mengikuti kegiatan selama tiga hari berturut-turut yaitu pada tanggal 13,14 dan 15 Juli 2020, pada akhir kegiatan guru diminta untuk mengisi evaluasi melalui Google Form. Berikut ini hasil evaluasi peserta terkait pelatihan dan workshop yang telah mereka ikuti (Gambar 15).

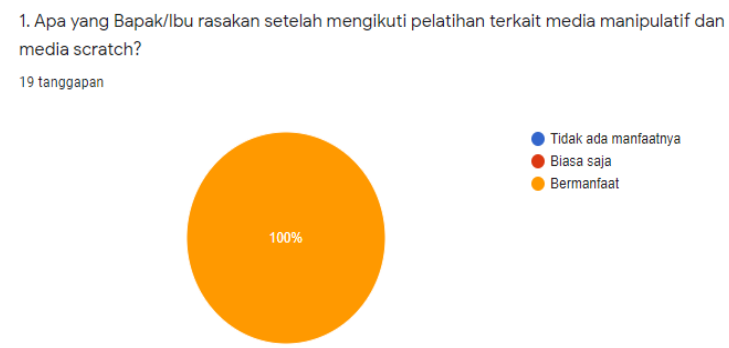

Gambar 15. Hasil post test tentang media manipulatif dan media scratch
Seratus persen atau 19 peserta yang memberikan evaluasi terhadap kegiatan ini, menyatakan bahwa pelatihan terkait media manipulatif dan media scratch sangat bermanfaat. Beberapa alasan mengapa peserta merasa pelatihan ini bermanfaat diantaranya: mendapatkan ilmu baru; menambah wawasan dalam menggunakan media pembelajaran; Dengan banyak media siswa lebih tertarik dalam pembelajaran; memudahkan dalam mengajar; sangat membantu dalam proses penanaman konsep bagi siswa dan sangat menarik. Tidak ada satupun peserta yang menyatakan bahwa pelatihan ini tidak ada manfaatnya atau biasa-biasa saja.

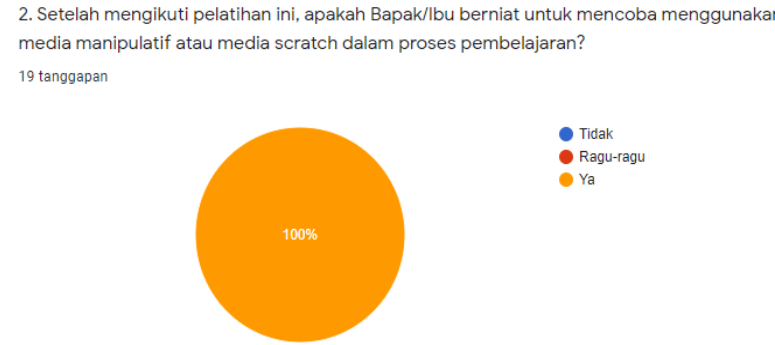

Gambar 16. Hasil evaluasi tentang minat menggunakan media manipulatif dan media scratch

Seratus persen atau 19 peserta yang memberikan evaluasi terhadap kegiatan ini, menyatakan bahwa mereka berniat untuk menggunakan media manipulatif dan media scratch dalam proses pembelajaran (Gambar 16). Beberapa alasan mengapa peserta merasa pelatihan ini bermanfaat diantaranya: untuk memudahkan siswa dalam belajar; lebih menarik; sangat membantu untuk pemahaman konsep; Disamping tampilan bagus untuk di minati anak-anak dan juga membantu untuk kegiatan pembelajaran; Mengenalkan media baru untuk siswa agar memudahkan siswa dalam memahami konsep; Media scratch lebih menarik buat anak anak, apalagi pada zaman sekarang; Peraga manipulatif menarik bagi anak sedangkan scratch sangat menarik dan sangat sesuai dengan kondisi kekinian yg serba IT. Tidak ada satupun peserta yang menyatakan tidak akan mencoba dan raguragu. Menurut Gunawan \& Al Irsyadi (2016), penggunaan teknologi komputer dapat meningkatkan pemahaman siswa didik lebih cepat. Selain itu, keunggulan penggunaan media manipulatif adalah dapat membantu memvisualkan konsep yang abstrak kepada siswa sehingga siswa mudah memahami suatu konsep pembelajaran matematika (Halidjah, 2014).

\section{KESIMPULAN}

Berdasarkan hasil dan pembahasan, kegiatan perencanaan sampai evaluasi dapat berjalan 
dengan baik dan lancar. Terjadi peningkatan pemahaman konsep perkalian bilangan pada siswa ABK dan kegiatan workshop berjalan dengan baik, yang dibuktikan dengan $100 \%$ guru-guru kelas dan guru mata pelajaran matematika antusias dalam mempraktekkan bahan manipulatif dan mampu membuat program scratch. Selain itu peningkatan pemahaman konsep perkalian bilangan bulat siswa $A B K$ sangat signifikan yang ditunjukkan dengan kemampuan siswa $A B K$ memecahkan masalah di post tes. Kegiatan ini dapat dilanjutkan pada sekolah-sekolah inklusi lainnya bahkan dapat dilakukan pada Sekolah Luar Biasa (SLB) untuk membantu pemahaman siswa yang berkebutuhan khusus dalam memahami konsep bilangan bulat.

\section{UCAPAN TERIMA KASIH}

Terimakasih kepada DRPM Kemenristekdikti yang memberikan hibah melalui skema Program Kemitraan Masyarakat (PKM), seluruh civitas akademika Universitas Madura, dan SDN Lawangan Daya 2 Pamekasan yang telah bersedia menjadi mitra.

\section{DAFTAR PUSTAKA}

Aisyah, N., Hawa, S., Somakim, S., Purwoko, P., Hartono, Y., \& AS, M. (2007). Pengembangan pembelajaran matematika SD. Jakarta: Dirjen Dikti Depdiknas. https://andridm72.files.wordpress.com/2014/12/peng embangan-pembelajaran-mtk.pdf

Amir, A. (2014). Pembelajaran matematika SD dengan menggunakan media manipulatif. Forum Paedagogik, 6(01), 72-89. http://jurnal.iainpadangsidimpuan.ac.id/index.php/JP/article/view/ 166

Gunawan, D., \& Al Irsyadi, F. Y. (2016). Pemanfaatan Pemrograman Visual Sebagai Alternatif Pembuatan Media Belajar Berbasis Game dan Animasi. Warta LPM, 19(1), 53-63. https://doi.org/10.23917/warta.v19i1.1984

Halidjah, S. (2014). Penggunaan Media Manipulatif dalam Pembelajaran Matematika untuk Meningkatkan Hasil Belajar Siswa di Sekolah Dasar. Jurnal Pendidikan Dan Pembelajaran Khatulistiwa, 3(4), 1-9. https://jurnal.untan.ac.id/index.php/jpdpb/article/vi ew/5342

Hermanto, H. (2010). Penyelenggaraan Pendidikan Inklusif Membutuhkan Keseriusan Manajemen Sekolah. JPK (Jurnal Pendidikan Khusus), 6(2), 65-82. https://journal.uny.ac.id/index.php/jpk/article/view/ 6737

Iskandar, R. S. F., \& Raditya, A. (2017). Pengembangan Bahan Ajar Projectbased Learning Berbantuan Scratch. Seminar Nasional Matematika Dan Aplikasinya 2017, http://repository.unair.ac.id/73915/

Jannah, U. R. (2013). Teori dienes dalam pembelajaran matematika. INTERAKSI: Jurnal Kependidikan, 8(2), 126-131.

http://ejournal.unira.ac.id/index.php/jurnal_interaksi/ article/view/324
Jannah, U. R., Amiruddin, M., \& Linarsih, Y. (2018). Guru Sekolah Dasar di Kec. Pademawu "Workshop Pembuatan Media dan Pembelajarannya dengan Menggunakan Kerang Kipas dan Kerang Bambu (Lorjuk)." Abdiku: Jurnal Pengabdian Kepada Masyarakat, 1(1), 26-39. http://publikasi.stkippgribkl.ac.id/index.php/JA/article/view/332

Jannah, U. R., Saleh, H., \& Wahidah, A. (2019). Scaffolding untuk Pembelajaran Matematika di Kelas Inklusi. JKPM (Jurnal Kajian Pendidikan Matematika), 5(1), 61-72. https://doi.org/10.30998/jkpm.v5il.5254

Loiacono, V., \& Valenti, V. (2010). General Education Teachers Need to Be Prepared to Co-Teach the Increasing Number of Children with Autism in Inclusive Settings. International Journal of Special Education, 25(3), 24-32. https://eric.ed.gov/?id=EJ909033

Muhsetyo, G., Krisnadi, E., Karso, K., Wahyuningrum, E., Tarhadi, T., \& Djamus, D. (2014). Pembelajaran Matematika SD. In Pembelajaran Matematika Berdasarkan KBK. Jakarta: Universitas Terbuka. http://repository.ut.ac.id/4137/

Peraturan Menteri Pendidikan Nasional Nomor 70 tahun 2009 tentang Pendidikan Inklusif (Pensif) Bagi Peserta didik yang Memiliki Kelainan dan Memiliki Potensi Kecerdasan dan/atau Bakat Istimewa. http://pdpt.unimus.ac.id/2012/wpcontent/uploads/2012/05/Permen-No.-70-2009tentang-pendidiian-inklusif-memiliki-kelainankecerdasan.pdf

Pratiwi, A., Syahri, W., \& Muhaimin, M. (2017). Pengembangan media game edukasi kimia menggunakan scratch pada anak tahapan operasional formal. Jurnal Pendidikan Kimia, 1(1), 19. https://repository.unja.ac.id/2631/

Resnick, M., Maloney, J., Monroy-Hernández, A., Rusk, N. Eastmond, E., Brennan, K., Millner, A., Rosenbaum, E., Silver, J., Silverman, B., \& Kafai, Y. (2009). Scratch. Communications of the ACM, 52(11), 60-67. https://doi.org/10.1145/1592761.1592779

Smith, J. D. (2006). Inklusi Sekolah Ramah untuk Semua. Bandung: Nuansa. http://opac.iaid.ac.id/index.php?p=show_detail\&id $=1781$ \&keywords $=$

Tarmansyah, T. (2007). INKLUSI: Pendidikan Untuk Semua. Jakarta: Depdiknas.

Undang-undang Republik Indonesia nomor 20 tahun 2003 tentang sistem pendidikan nasional. https://pusdiklat.perpusnas.go.id/public/media/regu lasi/2019/11/12/2019_11_1203_49_06_9ab7elfa524ba603bc2cdbeb7bff93c3.pdf 